\title{
A Life-Cycle Consumption Model with Ambiguous Survival Beliefs*
}

\author{
Max Groneck \\ CMR, University of Cologne \\ Alexander Ludwig \\ CMR, University of Cologne, MEA, Munich and Netspar, Tilburg \\ Alexander Zimper \\ University of Pretoria, South Africa
}

ThisVersion: February 2012

\begin{abstract}
On average, "young" people underestimate whereas "old" people overestimate their chances to survive into the future. We parameterize a learning model of subjective survival beliefs with psychological biases such that we replicate these patterns. We then combine this learning model with an otherwise standard life-cycle model of consumption and savings. In line with empirical findings we show that our agents consume more at younger ages and dissave less at old age than agents who perfectly foresee their survival probabilities. We also show that our information driven model yields similar predictions as a preference based hyperbolic discounting model.
\end{abstract}

Keywords: Life-cycle hypothesis, subjective survival rates

JEL Codes: D91, D83, E21

* Financial support from the Network for Studies on Pensions, Aging and Retirement (Netspar) is gratefully acknowledged. We thank Ben Heijdra and participants at the 2011 SAET conference, the CESIfo Conference on Macroeconomics, the CMR Macroeconomic Workshop, and the Netspar Pension Workshop 2012, for helpful comments.

Contact information: Max Groneck, CMR, University of Cologne, Germany (groneck@wiso.unikoeln.de); Alexander Ludwig, CMR, University of Cologne, Germany (ludwig@wiso.uni-koeln.de); Alexander Zimper, University of Pretoria, South Africa (alexander.zimper@up.ac.za) 


\section{Introduction}

One important element of life-cycle models of consumption and savings are agespecific survival rates. Testing these models requires knowledge of individual's subjective beliefs of their probabilities to survive in future periods. It is common in this literature though to assume that individual's beliefs are given as objective probability distributions. ${ }^{1}$ Only recently, researchers have focused on subjective survival probabilities and their deviations from lifetables. Data on subjective beliefs indicate a systematic bias. People tend to underestimate their life expectancy when they are "young" and overestimate it at older age. On the one hand, using objective survival rates thus results in biased predictions of consumption and savings decisions in life-cycle models. On the other hand, merely substituting elicited survival beliefs as subjective probabilities in a standard expected utility maximization problem fails short of appropriately accounting for the consequences of belief formation on life-cycle decisions.

We address these implications. We first parameterize a model of Bayesian learning of survival risk under ambiguity - developed by Ludwig and Zimper (2010) in order to replicate the aforementioned patterns of subjective survival beliefs in the data. Our model involves an interplay between an initial pessimistic bias and optimistic updating of survival beliefs as the agent gets older and receives more information. We refer to these beliefs as psychologically biased beliefs.

As a next step, we extend an otherwise standard stochastic life-cycle model with our model of survival belief formation. In line with empirical findings on household saving, we show that agents in our modified life-cycle model consume more at younger ages and dissave less at old age than agents who perfectly foresee their survival probabilities.

As to the data on subjective survival beliefs in the Health and Retirement Study (HRS) we find that the average 65 year old underestimates the objective probability to become 80 years by $28.6 \%$. This underestimation gets smaller with increasing age. Beyond age 80 agents start to overestimate their survival probability whereby the upward bias increases with age. Agents between ages 85 and 89 in the sample exhibit an overestimation way above $100 \%$ of the objective survival rate. As we further discuss, this pattern is representative for other micro datasets.

With regard to simulated savings behavior in our model we find that, on average, households with subjective survival beliefs at working age have a savings rate of

\footnotetext{
${ }^{1}$ For example, see Hurd (1989), Hubbard et al. (1995) or Imrohoroğlu et al. (2003).
} 
13.3 percent compared to a rational expectations model with an average savings rate of 21.3 percent. At older ages the agent with subjective probabilities dissaves less, with a rate of 38.5 percent on average compared to dissaving of 54.1 by a rational expectations agent. Overall, our life-cycle model with ambiguous survival beliefs leads to very different life-cycle behavior compared to a standard rational expectations model where mortality risk is correctly accounted for by the agent. We therefore claim that the observed biases in subjective survival beliefs add to explanations for the two empirical observations, undersaving for retirement and too little dissaving at older ages.

In contrast to standard models with (subjective) expected utility decision makers, the psychologically biased agents of our model make dynamically inconsistent decisions so that their realized consumption and savings differ from their plans. In this respect, our model shares similarities with the preference based (quasi-)hyperbolic discounting model, cf. Strotz (1956), Pollak (1968) and Laibson (1997) In fact, we can calibrate hyperbolic discounting functions such that the two models yield similar predictions with regard to life-cycle consumption and savings behavior. A problem of calibrating quasi-hyperbolic discounting models is, however, that additional preference parameters reflecting the degree of present-bias are not observable and there is not much consensus concerning their value. In contrast, our information based model exploits the information on subjective survival beliefs in the data. In addition, our model is based on a decision theoretic framework. We are thus "opening the black box of decision makers instead of modifying functional forms" as has been raised in the literature e.g. by Rubinstein (2003).

The remainder of our paper is structured as follows. In Section 2 we show data of subjective survival rates, present some stylized facts that we wish to address with the life-cycle model with subjective survival beliefs and review the literature. Section 3 sets up the life-cycle model with subjective survival beliefs. Section 4 lays out calibration details and section 5 presents results of a numerical version of the model. Section 6 concludes.

\section{Empirical Facts and Literature}

Considering subjective data on life expectancy rather than life table data in a lifecycle setting is expected to have significant effects on agents decision making because the observed biases are huge. The subjective data is taken from the Health and 
Retirement Study (HRS). In this survey people are asked their probability to survive from interview age $j$ up to a specific target age $k$ where target age is mostly between 10 and 15 years in advance. ${ }^{2}$ Figure 1 compares the resulting average subjective beliefs on survival of respondents with the corresponding objective data for three waves of the HRS between 2000 and 2004 .

Figure 1: Relative difference of subjective survival probabilities and cohort data
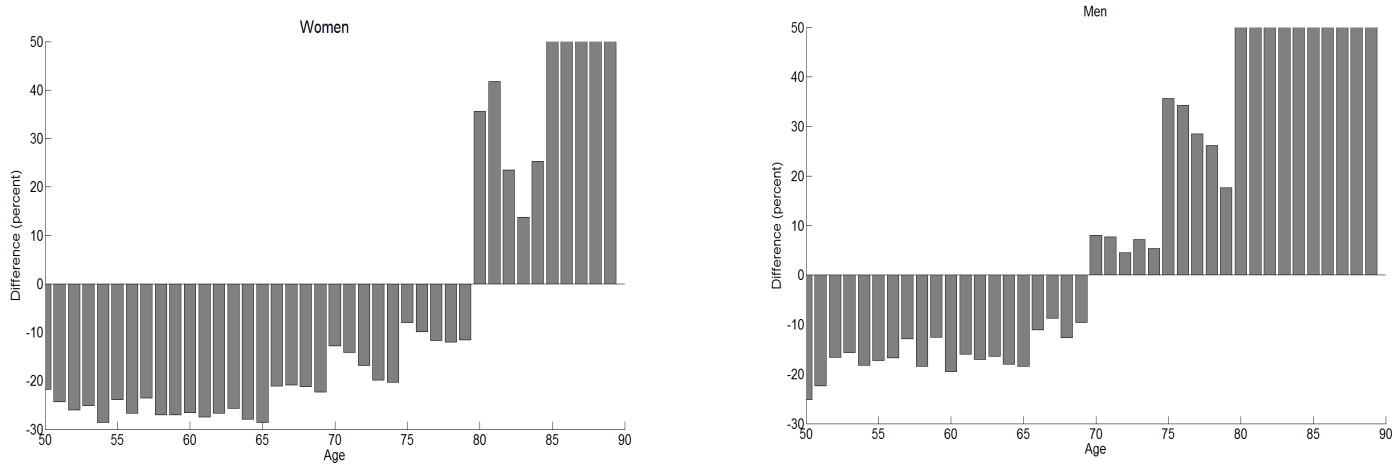

The columns are cut off at the $50 \%$ limit.

Cohort life table data is estimated with the Lee-Carter procedure

Source: Own calculations based on HRS, Human Mortality Database

and Social Security Administration data.

The figure shows that, on average, subjective expectations on mortality risk are underestimated at younger age, i.e., before the age of 70 for men and 80 for women and overestimated beyond that age. For example, the average 65 year old women in the HRS sample underestimates the objective probability to become 80 years by $28.6 \%$. The underestimation does get smaller with increasing age and at the age of 80 (for men at age 70 ) the agents begin to overestimate their survival probability whereby the upward bias increases with age. Women at age 85 and men at age 80 in the sample and beyond exhibit an overestimation way above $100 \%$ of the objective survival rate. ${ }^{3}$ Similar patterns can be observed in most European countries according to data from the Survey of Health, Ageing and Retirement in Europe (SHARE), cf. Peracchi and Perotti (2010).

We refer to these biases as "pessimism" at younger ages and "optimism" at older ages. Our concept of optimism is in line with insights from psychology where the implications of denying death have been taken more seriously than by economists. ${ }^{4}$

\footnotetext{
${ }^{2}$ People at ages 50 to 69 were asked the probability to survive up to 80, people at age 70 to 74 (75 to 79 ) were asked the probability to survive up to age 85 (90), and so forth.

${ }^{3}$ Observe that the columns in the figure are cut off at the $50 \%$ limit.

${ }^{4}$ A notable exception is Kopczuk and Slemrod (2005).
} 
For example, Kastenbaum (2000) summarizes the state of psychological research about attitudes towards death as follows: "there are divergent theories and somewhat discordant findings, but general agreement that most of us prefer to minimize even our cognitive encounters with death." For younger people the prospect of death is less relevant yet. Our concept of pessimism is based on the notion that households may underestimate the increase of life-expectancy due to technological progress.

To accommodate such psychological attitudes, Ludwig and Zimper (2010) develop a decision theoretic model of survival belief formation with psychological biases. The model can account for the overly optimistic life expectations of elderly people as well as the initial pessimistic biases of younger people. Ludwig and Zimper (2010) further estimate the parameters of the theoretical model and demonstrate that a parsimonious representation of survival belief formation matches well the average patterns observed in the data.

We incorporate this model of subjective survival belief formation into a stochastic life-cycle model and study the effects on life-cycle economic decision making. Our approach is most similar to recent models of behavioral economics which shed light on several phenomena of economic decision making that cannot be explained by standard rational expectations models. This line of research highlights features such as bounded rationality, and bounded self-control, see Mitchell and Utkus (2005) for a review. Bounded rationality refers to the fact that some decisions and problems may be too complex for individuals to master perfectly right. Studies report large gaps between self-reported behavior and self-reported plans and/or preferences.

Bernheim and Rangel (2007), and Laibson et al. (1998) quote numerous studies indicating self-reported mistakes in terms of private savings decisions for retirement. Generally, people seem to save less for retirement than they actually planned and they save less than they think they should do. For example, Choi et al. (2006) and Ameriks and Utkus (2006) find that two thirds of respondents reported saving rates that are "too low" compared to their ideal savings rate. Bernheim (1998) evaluates US household survey data and finds that people at ages 29 to 47 seem to be relatively little aware of their financial vulnerabilities: $54 \%$ of the lowest wealth quintile feel well prepared for retirement. ${ }^{5}$ According to the National Retirement Risk Index published by the Center for Retirement Research at Boston College $51 \%$ of working age households are at risk of being unable to maintain their pre-retirement standard of living in retirement (Munnell et al. (2010)). ${ }^{6}$ Similarly, Barsky et al. (1997) finds

\footnotetext{
${ }^{5}$ As will be argued later, this might also be due to the fact that people underestimate their remaining life expectancy rather than being overly optimistic.

${ }^{6}$ Whether households in the US are not saving enough for retirement is an open debate. See
} 
in an experimental study that, on average, people have a preference for an upward sloping consumption path. This target is inconsistent with the observed low saving rates of the US baby-boomers.

Moreover, insights from psychology indicate that people do not have perfect foresight. Studies confirm a tendency of individuals for dynamically inconsistent behavior. Individuals might have right intentions or beliefs but they lack the willpower to carry out the appropriate changes in behavior. Inspired by laboratory and field studies of time preferences a large theoretical literature dealing with bounded selfcontrol problems emerged, see e.g. Laibson (1997), O’Donoghue and Rabin (1999), or Gul and Pesendorfer (2001). ${ }^{7}$

Besides a tendency for undersaving and time-inconsistent behavior a well-known puzzle within the standard life-cycle framework à la Ando, Brumberg and Modigliani (Modigliani and Brumberg (1954), Ando and Modigliani (1963)) is that people hold large amounts of assets still late in life and dissave less at the end of their life than predicted with standard life-cycle models. ${ }^{8}$ There are numerous possible explanations for this observed life-cycle pattern with yet no consent achieved. ${ }^{9}$

Overall, accounting for the biases in subjective survival beliefs in a life-cycle model might add to explanations for all three stylized facts: First, undersaving for retirement might partly be due to an underestimation of the true survival rates when young. Second, less dissaving at the end of life than predicted with standard life-cycle models might in part be explained by an overestimation of life expectancy at older ages. Third, people do not have perfect foresight which is accounted for in our model where the agents revise their plans when they get older.

The phenomena of undersaving and dynamically inconsistent behavior have already been studied in the context of hyperbolic discounting models. Here, presentbiased preferences of consumers have been incorporated into life-cycle models. For example, Laibson (1996) reports undersaving of hyperbolic consumers in life-cycle models relative to a normative savings rate.

Scholz et al. (2006) for opposite findings and Engen et al. (1999) for a discussion of several studies.

${ }^{7}$ Extensions of these models are numerous: Harris and Laibson (2001) studies hyperbolic discount functions in a stochastic setting with borrowing constraint, Gul and Pesendorfer (2004) study the consequences of self-control problems in an infinite horizon consumption model with uncertainty.

${ }^{8}$ See Hurd and Rohwedder (2010) for data on old-age dissaving. We abstract from the so called retirement-consumption puzzle. Recently, it has been questioned whether this puzzle exists at all once consumption expenditures are correctly accounted for. See Aguila et al. (2011) for further details.

${ }^{9}$ The two main explanations for large assets holdings late in life are bequest motives (Hurd (1989)), and precautionary savings due to possibly large health expenditures (De Nardi et al. $(2010))$. 
A problem of calibrating these studies is that additional preference parameters reflecting the degree of present-bias are hard to observe and there is not much consensus concerning their values. As opposed to this stream of literature, our framework constitutes an information based rather than a purely preference based approach. In consequence, the parameters necessary to calculate subjective survival probabilities can be directly estimated from the data on subjective survival beliefs. Thus, our approach seems quantitatively more reliable. ${ }^{10}$

While deviations from exponential discounting have been studied extensively, only few studies have looked at peoples' subjective beliefs about their own life expectancy and the consequences in life-cycle models. Initiated by Hammermesh (1985), empirical researchers have become interested in using data on subjective expectations in such and related studies. ${ }^{11}$ Recently, a few studies find significant effects of subjective survival beliefs for economic decision making that strongly support our approach. In particular, using the HRS data set, Bloom et al. (2006) find that increased subjective survival probability leads to higher wealth accumulation for couples confirming the result of an earlier study conducted by Hurd et al. (1998) estimating the correlation between subjective survival beliefs and saving behavior. The findings are consistent with the view that an overestimation of life expectancy lead to higher wealth accumulation. Gan et al. (2004) estimate a life-cycle model with bequest using subjective survival rates and get a better fit compared to the model with life table data. Recently, Gahramanov (2011) incorporates ad-hoc subjective survival rates into a life-cycle model and simulates profiles for different kinds of possible misperceptions of the true survival rate. We extend this line of research by incorporating a decision theoretic model of subjective survival belief formation into a life-cycle framework which is able to account for undersaving at younger ages, too little dissaving at older ages and time inconsistency at once.

Finally, observe that constructing simple heuristic subjective survival rates from the HRS survey data leads to qualitatively similar life-cycle patterns as our model of ambiguous beliefs. A severe conceptual shortcoming of such ad hoc approaches, however, is the lack of a well-defined (representative) agent who learns in a Bayesian fashion over his life-cycle information about his survival prospects. In contrast, our model of subjective belief formation is based on a sound decision theoretic framework that allows for biased Bayesian learning of a representative agent over his life-cycle.

\footnotetext{
${ }^{10} \mathrm{As}$ we discuss in the concluding section this will be even more valuable once we extend our framework to analyze welfare implications of biases in survival beliefs.

${ }^{11}$ See Hurd and Smith (1999), Attanasio and Hoynes (2000), and Puri and Robinson (2005).
} 


\section{Life-cycle model with subjective beliefs}

Life-time utility of the household is modeled in a standard time-separable way

$$
\mathrm{E}_{\psi, \eta}\left\{\sum_{k=t}^{T} \psi_{t, k} \beta^{k-t} u\left(c_{k}\right)\right\} .
$$

Expected lifetime utility consists of the sum of all per period utility functions $u(\cdot)$ discounted with the factor $\beta$ and weighted with the subjective probability $\psi_{t, k}$ to survive from period $t$ to $k$. The agent derives utility from consumption $c$ and dies for sure at period $T+1$. The expectations operator represents uncertainty with respect to the survival probability and stochastic labor productivity. Thus, agents in the model face two kinds of uncertainty. They are uncertain about their true probability to survive and they are unsure about their future income realization. We assume these two sorts of risk to be orthogonal to each other so that they can be isolated implying lifetime utility to be

$$
\sum_{k=t}^{T} \beta^{k-t} \cdot \mathrm{E}_{\eta}\left[u\left(c_{k}\right)\right] \cdot \mathrm{E}_{\psi}\left[\psi_{t, k}\right]
$$

The sole reason for stochastic labor productivity in our model is to impose discipline on calibration. For sake of comparability, our fully rational model should therefore feature standard elements as used in numerous structural empirical studies, as, e.g., by Gourinchas and Parker (2002), Kaplan and Violante (2010), Laibson et al. (1998) and several others. With respect to labor productivity we consequently assume that the agent is perfectly rational with von-Neuman-Morgenstern expectations $\mathrm{E}_{\eta}\left[u\left(c_{k}\right)\right]$ while $\eta$ is the labor productivity shock described in more detail below. On the contrary, for the expected survival rate $\mathbf{E}_{\psi}\left[\psi_{t, k}\right]$ we assume a rational Bayesian learning model with a psychological bias as proposed by Ludwig and Zimper (2010). The psychological bias is modelled by nesting the Bayesian learning model into a Choquet Expected Utility (CEU) function as proposed by Schmeidler (1989). 


\subsection{Subjective survival beliefs}

Merging the subjective survival belief model into a life-cycle framework leads to the following lifetime utility function.

$$
\mathbb{C} \mathbb{E} \mathbb{U}_{h}=\sum_{k=t}^{T} v_{t, k}^{h} \beta^{k-t} \mathrm{E}\left[u\left(c_{k}\right)\right]
$$

where $\mathbf{E}_{\psi}\left[\psi_{t, k}\right]=v_{t, k}$ is denoted as the subjective belief to survive from period $t$ to period $k$, planned in period $h \leq t<k$, given by:

$$
\nu_{t, k}^{h}=\delta_{h} \cdot \lambda+\left(1-\delta_{h}\right) \tilde{\psi}_{t, k}^{h}
$$

Equation (4) corresponds to the subjective survival belief developed in Ludwig and Zimper (2010). They lay out a parsimonious version of their model resulting in a specification of the representative agent's survival belief pattern with a vector of only three parameters. In the following, we briefly sketch the model while the details and the decision theoretic foundation are provided in their paper. The details of how to incorporate the decision theoretic model into a life-cycle framework are laid out in the appendix.

The subjective survival belief (4) consists of two parts: a Baysian learning probability $\tilde{\psi}_{t, k}^{h}$ and a so-called optimism parameter $\lambda$ coming from the specific form of the Choquet expected utility function. The two parts are weighted with the ambiguity parameter $\delta_{h}$ which is increasing in age. In the data the dynamics of subjective belief formation are from pessimism at younger ages (underestimation of survival probabilities) to optimism at older ages (overestimation). This pattern is generated in the model by an initial underestimation of the Bayesian learning probability and a rather low initial ambiguity parameter $\delta_{h}$. With increasing age, the agent learns the true survival probability in a Bayesian fashion but at the same time she gets more ambiguous with higher age. Thus, the older the agent gets the more weight is put on the optimism parameter $\lambda$, eventually leading to an overestimation of the survival rates.

The planing period $h$ is crucial in forming subjective survival beliefs as it will be linked to the information the agent has gathered when forming her beliefs. In most cases, $h$ and $t$ will coincide, but the distinction is relevant for subjective belief formation of future periods planned at age $h$.

The Bayesian probability to survive from period $t$ to $k$, planned in period $h$ is 
specified as follows:

$$
\tilde{\psi}_{t, k}^{h}=\frac{2}{2+\zeta h} \phi^{k-t} \psi_{t, k}+\frac{\zeta h}{2+\zeta h} \psi_{t, k}
$$

The first term represents the prior estimate of the true survival probability, initialized at $\phi^{k-t} \psi_{t, k}$. Intuitively, the agent initially has an estimation error about her survival rate which is the bigger the more $\phi$ is biased away from one. The second term stands for the new information the agent gathers. In the parsimonious model of Ludwig and Zimper (2010) it is assumed that new information corrensponds to the true survival probability even though the agent is not aware of this. Rather, information received by the agent is linked to the planning age by a special experience function $\zeta h$, i.e., the amount of gathered information. Parameter $\zeta$ captures the speed of the learning process by putting more weight on the new information with increasing age. Put together, the Bayesian probability is given by:

$$
\tilde{\psi}_{t, k}^{h}=\left(\frac{2 \phi^{k-t}+\zeta h}{2+\zeta h}\right) \psi_{t, k} .
$$

Eventually the Bayesian probability converges to the true survival rate $\psi_{t, k}$ for $h$ large enough. This is in line with standard results on the consistency of additive Bayesian estimators, in particular Doobb's consistency theorem (Doob (1949)). The convergence property is, however, inconsistent with the pattern of subjective beliefs, cf. figure 1. As individuals age, subjective beliefs converge towards their objective counterparts but then overshoot by being overly optimistic.

To accommodate these biases, the Bayesian learning model is nested in a CEU function implying a degree of ambiguity that is also rising with age. Ambiguity $\delta_{h}$ evolves according to

$$
\delta_{h}=\frac{\delta}{\delta+(1-\delta) \frac{1}{1+\zeta h}}
$$

where $\delta$ is initial ambiguity to be estimated. In equation (4), the degree of ambiguity determines how much weight the agent puts on the optimism factor $\lambda$. Ambiguity is increasing with age, which can account for the fact that older people overestimate their survival probability. Note that $\lim _{h \rightarrow \infty} \delta_{h}=1$ so in the limit all weight is put on $\lambda$.

To summarize: The parsimonious model of Ludwig and Zimper (2010) results in a specification of the representative agent's survival belief pattern with a vector of only three parameters $\Psi=[\phi, \delta, \lambda]$. These parameters reflect (i) an initial bias in the additive estimator, i.e., overestimation for $\phi>1$, or underestimation for $\phi<1$, (ii) a measure for initial ambiguity, $\delta$, and (iii) the degree of optimism, 
respectively pessimism, by which the agent resolves her ambiguity, $\lambda$. Note, that the CEU model nests rational expectations (RE) as a special case. If we set $\delta=0$ and $\phi=1$, the subjective probability boils down to the objective counterpart, and $\nu_{t, k}^{h}$ can be replaced by $\psi_{t, k}$ in equation (3).

\subsection{Time inconsistency and agent types}

The non-additive nature of subjective survival probabilities give rise to time inconsistency. Note that the non-additive subjective beliefs imply

$$
\nu_{t, k} \neq \Pi_{\tau=t+1}^{k}\left[\nu_{\tau-1, \tau}\right]
$$

We thus need to distinguish between planned and realized variables and can state the following proposition.

Proposition 1 For a CEU maximizer, the marginal rate of substitution (MRS) between consumption in two periods depends on the planning period. For $h<t<k$, $h+i \leq t$ and $i>0$ :

$$
M R S_{c_{t}, c_{k}}^{h} \neq M R S_{c_{t}, c_{k}}^{h+i}
$$

The proof is given in the appendix.

As a consequence, a CEU agent makes her plan for the whole life-cycle but only executes the first-periods consumption and savings plan. At the next period she gains new information, updates her survival beliefs and has to make an entirely new life-cycle plan. Of course, for a RE agent there is no time inconsistency. The marginal rate of substitution is independent of the planning period, because the unconditional survival rate can be expressed as the product of the conditional survival rates.

Due to time inconsistency one must take a stand on how the agent perceives his own behavior when forming survival beliefs. We distinguish three different individuals according to their beliefs with regard to their expected values in the future.

Definition 1 We define an individual's belief as being the type

(i) Rational expectations (RE): $\delta=0$ and $\phi=1$

(ii) non-anticipating agent (CEU): constant experience $h$ when making her plan

(iii) anticipating agent (SCEU): time-varying experience $h=t$ when making her plan. 
Generally, in models with time inconsistency there is a distinction between sophisticated agents who foresee their future time inconsistent behavior and naive agents who think they will behave rational in the future, cf. O'Donoghue and Rabin (1999). Our definition of types differs from this literature because in our model time inconsistency does not arise out of self-control problems but because of a lack of information. Using the concept of a naive agent in our model would imply using subjective survival probabilities in the current period and objective probabilities for all future periods. This is implausible in our information driven model. Instead, we distinguish between a "non-anticipating" agent and an "anticipating" agent, and use the rational expectations agent as a benchmark case.

The non-anticipating agent (CEU) captures the idea of a naive agent as it is assumed that she does not foresee that she will gain experience when making her consumption plans. This is expressed formally with a constant $h$. As the agent survives to the next period she updates her beliefs when gaining another year of experience. The non-anticipating agent will be used for the simulation below.

The anticipating agent (SCEU) can be interpreted as the counterpart of a sophisticated agent. This agent foresees that she will gain experience in the future. The concept implies that the agent exactly knows how much experience she will gain when making her plan. This is logically inconsistent with the notion of learning. Therefore, while introducing the concept of a SCEU agent is useful for sake of comparison, we will not consider it any further for the remainder of our analysis.

Observe that the key driver of dynamic inconsistency is the structure of nonadditive beliefs. If we assume a non-anticipating agent who does not foresee that she will gain experience in the future, we also have time inconsistency from rational Bayesian learning alone. Note that this is not the case for an anticipating agent and can be attributed to the assumption of constant experience when making her plan, see the proof of proposition 1 for further details.

\subsection{Dynamic problem}

The per period utility function is CRRA

$$
u\left(c_{t}\right)=\frac{c_{t}^{1-\theta}}{1-\theta}, \text { for } \theta<1
$$

in any period $t$. The restriction $\theta<1$ implies positive utility. We impose it because of our normalization of zero utility in case of death, see the appendix for further details. 
Risky labor income is modeled in a standard fashion. It is assumed that labor productivity is exposed to idiosyncratic shocks $\eta \in\{1, \ldots, E\}$ that follows a time invariant Markov process with transition probabilities

$$
\pi\left(\eta^{\prime} \mid \eta\right)>0
$$

The unique invariant distribution of $\pi\left(\eta^{\prime} \mid \eta\right)$ is defined by $\Pi\left(\eta^{\prime} \mid \eta\right)$. Recall that we do not assume any ambiguity nor learning behavior, here. The agent is perfectly rational with respect to her productivity risk. In addition, labor productivity differs by age: $\varepsilon_{t}$ denotes average age-specific productivity.

We assume a pure PAYGO public social security system. The government sets a flat payroll tax $\tau$ on labor earnings and pays pension benefits $b$ to retired households that are independent on the shock history of the wage processes. The government budget is assumed to be balanced each period and is given by

$$
\tau w \sum_{t=0}^{T^{r}-1} \varepsilon_{t} N_{t}=\xi \sum_{t=T^{r}}^{T} N_{t}
$$

where $w$ is gross wage assumed to be constant, $\xi$ is the net pension benefit level and $N_{t}$ is the fraction of households in period $t$.

Income of the households in period $t$ is given by

$$
y_{t}= \begin{cases}\eta \varepsilon_{t} w & \text { for } t<T^{r} \\ b=\xi(1-\tau) w & \text { for } t \geq T^{r}, 0 \leq \xi<1\end{cases}
$$

where $T^{r}$ is the first period of retirement. There are no annuity markets and accidental bequests are taxed away. This assumption can be justified by the observed small size of private annuity markets. ${ }^{12}$

Cash-on-hand $x_{t}$ is defined as the sum of last periods assets $a_{t}$ including interests and income today $y$

$$
x_{t}=a_{t}(1+r)+y_{t},
$$

where interest rate $r$ is fix. The budget constraint is given as

$$
a_{t+1}=x_{t}-c_{t} \geq 0
$$

where a no borrowing constraint is assumed. Gross savings are equal to assets

\footnotetext{
${ }^{12}$ See Friedman and Warshawsky (1990). Observe that the optimistic beliefs we observe in the data accelerate the annuity puzzle, cf., e.g. Brown (2007).
} 
tomorrow $s_{t}^{g}=a_{t+1}$.

The model is solved recursively. To set up the Bellman equation we have to use unconditional subjective survival beliefs (see equation (7)). The agent makes her plan at $h$. The recursive maximization problem of the household between two periods $t>h$ reads as follows:

$$
\begin{aligned}
V_{t}^{h}\left(a_{t}, \eta\right)= & \max _{c_{t}, a_{t+1}}\left\{u\left(c_{t}\right)+\beta \frac{v_{h, t+1}}{v_{h, t}} \sum_{\eta^{\prime}} \pi\left(\eta^{\prime} \mid \eta\right) V_{t+1}^{h}\left(a_{t+1}, \eta^{\prime}\right)\right\} \\
& \text { s.t. } \\
a_{t+1}= & a_{t}(1+r)+y_{t}-c_{t} \\
a_{t+1} \geq & 0
\end{aligned}
$$

From the first order conditions we derive the a modified Euler-equation

$$
\begin{aligned}
u_{c_{t}} & \geq \beta \frac{v_{h, t+1}}{v_{h, t}} \sum_{\eta^{\prime}} \pi\left(\eta^{\prime} \mid \eta\right) u_{c_{t+1}}(1+r) \\
& =\text { if } a_{t+1}>0
\end{aligned}
$$

with the inequality relation due to the borrowing constraint. Observe that we have to use the ratio of unconditional subjective survival beliefs $\frac{v_{h, t+1}}{v_{h, t}}$ instead of the conditional survival rate due to the non-additive nature of the probabilities.

Wealth dispersion is only driven by productivity shocks. We denote the crosssectional measure of households at period $t$ by $\Phi_{t}$ and the Markov transition function by $Q_{t}$.

Denote by $\mathcal{A}=[0, \infty]$ the set of all possible asset holdings, $\mathcal{E}$ the set of all possible income realizations and $\mathcal{T}$ the set of all possible age realizations. Further, define by $\mathcal{P}(\mathcal{E})$ and by $\mathcal{P}(\mathcal{T})$ the power sets (the sets of all subsets) of $\mathcal{E}$ and $\mathcal{T}$, respectively and by $\mathcal{B}(\mathcal{A})$ the Borel- $\sigma$-algebra of $\mathcal{A}$. Let $\mathcal{Y}$ be the kartesian product $\mathcal{Y}=\mathcal{T} \times \mathcal{E} \times \mathcal{A}$ and $\mathcal{M}=(\mathcal{Y}, \mathcal{B}(\mathcal{A}))$. The measures $\Phi_{t}$ will be elements of $\mathcal{M}$. The cross-sectional measure evolves according to

$$
\Phi_{t+1}(\mathcal{T} \times \mathcal{E} \times \mathcal{A})=\int Q_{t}((t, \eta, a), \mathcal{T} \times \mathcal{E} \times \mathcal{A}) \cdot \Phi_{t}(d t \times d \eta \times d a)
$$

where the Markov transition function is given by

$$
Q_{t}((t, \eta, a), \mathcal{T} \times \mathcal{E} \times \mathcal{A})= \begin{cases}\pi(\eta, \mathcal{E}) \cdot \psi_{t, t+1}, & \text { if } a_{t+1}(t, k, \eta, a) \in \mathcal{A}, t+1 \in \mathcal{T} \\ 0 & \text { else }\end{cases}
$$


for all $(t, \eta, a) \in Y$ and all $(\mathcal{T}, \mathcal{E}, \mathcal{A}) \in \mathcal{Y}$. $Q_{t}$ is the probability that an agent at current age $t$ in income state $\eta$ and with assets $a_{t}$ will end up with age $t+1$, in income state $\eta^{\prime}$ and with assets $a_{t+1} \in \mathcal{A}$. The transition function determines the distribution of assets in the next period given the distribution today. It describes the fraction of people with age in $\mathcal{T}$ income states in $\mathcal{E}$ and assets in $\mathcal{A}$ transit to $(\mathcal{T}, \mathcal{E}, \mathcal{A})$ in $t+1$ as measured by $Q_{t}$. Population is normalized to unity.

\section{Calibration}

In the following, we first describe the calibration process. Most of the structural model parameters in our model are either calibrated by reference to other studies, based on empirical estimates or implied by these values. We refer to these exogenous parameters as first stage parameters. A second subsect is calibrated endogenously by informally matching specific moments in the data. We refer to these endogenous parameters as second stage parameters. In our benchmark model, the only second stage parameter is the household discount factor.

We calibrate the model to the US economy. Table 1 summarizes all calibration parameters. The production technology is assumed to be of a standard CobbDouglas type $Y=K^{\alpha} L^{1-\alpha}$, where Output $Y$ is produced with Labor $L$ and Capital $K$. Perfect competition is assumed on the firm side. We assume a small open economy in steady state such that the interest rate is exogenous and gross wages are constant. The interest rate is taken to be $r=0.042$ which is the average real rate of return of stocks and long-run bonds for the US between 1946 and 2001, estimated by Siegel (2002), table 1.1 and 1.2. The US capital-output ratio is set to $\frac{K}{Y}=2.65$ and the output share of capital is $\alpha=0.3{ }^{13}$

Observe that perfect competition in the firm sector implies that $r=\alpha \frac{Y}{K}-\iota$ where $\iota$ is the depreciation rate to capital. For our given level of the capital output ratio of 2.65, our estimate of $\alpha=0.3$ and an interest rate of $r=0.042$ we readily obtain the corresponding depreciation rate of $\iota=0.071 .^{14}$ Perfect competition also gives the standard alternative representation of the interest rate as $r=\alpha k^{\alpha-1}-\iota$ and of the wage rate as $w=(1-\alpha) k^{\alpha}$. These two equations imply that $w=\left(\frac{\alpha}{r+\iota}\right)^{\frac{\alpha}{1-\alpha}}$. From this we get the wage rate as $w=1.063$.

For the social security contribution rate we take the US average $\tau=0.124$. The

\footnotetext{
${ }^{13}$ These numbers are standard in the literature. They are computed from NIPA tables provided by BEA.

${ }^{14}$ Notice that the depreciation rate is only an auxiliary object in our model. It translates capital accumulation via the marginal product of capital condition into our target interest rate.
} 
pension benefit level then follows from the social security budget constraint whereby we assume a balanced budget.

The values of the persistence of the income shock and the implied conditional variance are taken from Krüger and Ludwig (2007) based on Storesletten et al. (2004). The age specific productivity of wages is estimated based on PSID data applying the method developed in Huggett et al. (2007) (assuming cohort effects).

Values for parameters that describe formation and updating of subjective survival beliefs, i.e., $\xi, \phi, \delta, \lambda$, are taken from Ludwig and Zimper (2010). ${ }^{15}$

Table 1: First stage parameters

\begin{tabular}{ll}
\hline \hline & First stage parameters \\
\hline Technology and prices & \\
\hline$\frac{K}{Y}=2.65$ & Capital-Output ratio \\
$w=1.063$ & Gross wage \\
$r=0.042$ & Interest rate \\
$\iota=0.071$ & Depreciation rate \\
$\alpha=0.3$ & Share of capital \\
$\tau=0.124$ & Social security contribution rate \\
$\xi=0.322$ & Net pension benefit level \\
\hline Income process & \\
\hline$\tilde{\rho}=0.97$ & Persistence of the income shock \\
$\tilde{\sigma}^{2}=0.08$ & Variance of the income shock \\
$\left\{\varepsilon_{t}\right\}$ & Age specific productivity estimated from PSID \\
\hline Preferences & \\
\hline$\theta=0.99$ & Parameter of relative risk aversion \\
\hline Subjective survival beliefs & \\
\hline$\xi=10$ & Speed of the learning process \\
$\phi=0.897$ & Initial bias \\
$\delta=0.002$ & Degree of ambiguity \\
$\lambda=0.412$ & Degree of optimism \\
\hline Age limits and survival data & \\
\hline$T^{r}=45$ & Retirement \\
$T+1=91$ & Certain death \\
\hline$\psi_{t, k}$ & objective survival rates computed from SSA and HMD \\
\hline \hline
\end{tabular}

Households enter the model at age 20 (model age $t=1$ ). The last working year is assumed to be age 64 , hence $T^{r}=45$. Certain death happens at the age

\footnotetext{
${ }^{15}$ See Table 5, p. 22 in Ludwig and Zimper (2010). Their estimation results are for men and women so we take the average of the estimated parameters assuming the same weight fo men and women to get an approximation for $\phi, \lambda$ and $\delta$ for the total population. This approach is a fair estimation of otherwise first pooling the subjective beliefs and reestimate the model of Ludwig and Zimper (2010) for the total population.
} 
of 110 , hence $T+1=91$, a choice which we justify below. For the objective survival rates we estimate cohort specific survival rates for US cohorts alive in 2007. The objective cross sectional data is taken from the Social Security Administration (SSA) for 1990-1933 and the Human Mortality Database (HMD) for the years 1934-2007. We estimate cohort survival rates for the year 2007 using the Lee-Carter procedure (Lee and Carter (1992)) decomposing the average objective survival probability in age-specific constant terms $a_{t}$ and $b_{t}$ and a time specific factor $d_{p}$. The hazard rate $\mu_{t, p}=1-\psi_{t, t+1}$ at age $t$ in period $p$ is assumed to follow

$$
\log \left(\mu_{t, p}\right)=a_{t}+b_{t} d_{p}
$$

The time series process of $d_{p}$ is assumed to follow a unit root with drift:

$$
d_{p}=\lambda+d_{p-1}+\epsilon_{p}
$$

where $\epsilon_{p} \sim \mathcal{N}\left(0, \sigma_{\epsilon}^{2}\right)$. Since data of survival rates is unreliable for ages past 100 we estimate survival rates for ages past 100 assuming that mortality follows the Gompertz-Makeham law. ${ }^{16}$ The mortality rate $\mu_{t}$ is assumed to follow

$$
\mu_{t}=\alpha_{1}+\alpha_{2} \cdot \exp \left(\alpha_{3} \cdot t\right)
$$

at age $t$. We estimate the parameters $\alpha_{1}, \alpha_{2}$ and $\alpha_{3}$ to get an out of sample prediction for the ages past 100 . The resulting predicted mortality rate function fits actual data very well and is used as objective cohort data in the simulation. According to our estimates the average mortality rate approaches 1 at ages around 110 . We thus assume a terminal age where the agent dies for sure at 110 .

As to the second stage parameters, we calibrate the model by choosing a discount factor $\beta$ that matches the capital-output ratio of 2.65 .

Table 2: Second stage parameters

\begin{tabular}{lll}
\hline & Preferences & Targets \\
\hline$\beta=0.964$ & Subjective discount factor & $\frac{K}{Y}=2.65^{1)}$ \\
$\gamma=0.822$ & Hyperbolic discounting factor & $\min _{\gamma}\left[\nu_{h, t} \beta^{t-h}-\psi_{h, t} \delta \beta^{t-h}\right]^{2} \forall t, h^{2)}$ \\
\hline \hline${ }^{1)}$ Capital-output ratio; ${ }^{2)}$ mimimize distance of effective discount functions
\end{tabular}

This discount rate is also used for the RE agent. Of course, this leads to a different capital-output ratio for the RE agent. But the aim of the simulation

\footnotetext{
${ }^{16}$ See Preston et al. (2001), p. 192.
} 
is precisely to study different consumption and savings behavior for agents with subjective and objective beliefs with the same preferences. We will discuss this approach in section 5.2. For the hyperbolic discounting model we calibrate the short term discount factor as an additional parameter. The procedure of this approach is described below.

\section{Results of the numerical model}

The life-cycle decisions of savings and consumption with subjective survival beliefs will be compared with two models: the RE agent and the (Quasi-)Hyperbolic agent. Both of these agents also have to take expectations with respect to uncertain labor income but they have no uncertainty concerning their rate of survival and use objective data. While the RE agent will serve as a benchmark agent a comparison with the hyperbolic agent shows close similarities to the CEU model.

Before studying the life-cycle profiles we study the different parts of the subjective survival belief model in isolation and compare the subjective beliefs to the estimated life table cohort data.

\subsection{Understanding subjective survival beliefs}

Before studying the life-cycle consumption and saving profiles of agents the subjective probabilities are studied more closely. From the data we know that young agents tend to underestimate survival probabilities in the distant future whereas older agents overestimate this probability. The data does not say anything about the conditional probabilities to survive to the next period.

In the following, the subjective survival rates from a non-anticipating agent resulting from the decision theoretic model will be compared to the objective cohort data from life tables. To get a better understanding of how subjective beliefs are formed, we disentangle the probability in the two effects described above: Bayesian learning and ambiguity. We highlight the probability distribution with constant experience as these are the values considered by the agent when making her life-cycle plan. Note that this implies that there is no learning nor increased ambiguity when the target age rises. 


\section{Bayesian learning}

The Bayesian probability is calculated with equation (5). Ludwig and Zimper (2010) estimate the parameter $\phi$ to be smaller than one implying an initial underestimation of the true probabilities. The term $\phi^{k-t}$ converges to zero for higher target ages (large $k$ ). When making her plan experience $\zeta h$ stays constant and the term in the brackets converge to $\frac{\zeta h}{2+\zeta h}$ for $k$ large. Only when surviving to the next period the agent gains more experience and the term in the brackets eventually converges to 1 , implying that the agent learns the true probability. Compared to the objective data the conditional Bayesian probabilities depict an underestimation that gets smaller over time but remains also at old ages. For unconditional Bayesian probabilities the relative difference to the objective unconditional probabilities steadily increases for higher target ages.

\section{Ambiguity}

To isolate the effect of ambiguity, figure 2 plots the subjective unconditional probability $\nu_{t, k}$ given in equation (4) against the unbiased Bayesian learning part $\tilde{\psi}_{t, k}$ in a stylized way assuming a constant experience. The solid line plots any difference of the subjective survival belief to the Bayesian probability that is due to ambiguity. Obviously, with no ambiguity, i.e. for $\delta_{h}=0$, the subjective and the Bayesian probability coincide.

Figure 2: Unconditional probabilities for a young agent
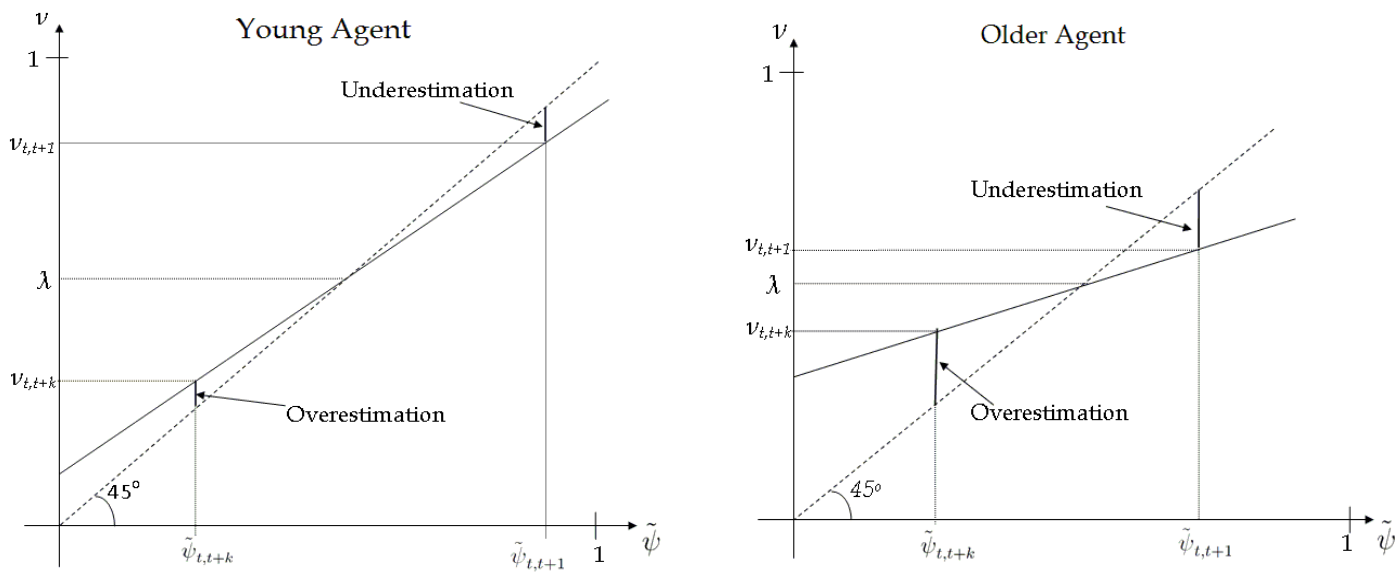

With ambiguity, the subjective belief can either be lower or higher than the Bayesian probability. When young (left panel of figure 2), the agent has has an 
additive conditional probability $\tilde{\psi}_{t, t+1}$ close to one and has not gained much experience (low ambiguity parameter $\delta_{h}$ ). The subjective probability line is close to the 45-degree line. For survival rates in the near future the subjective survival rate is smaller than the Bayesian probability (underestimation) since the size of ambiguity $\lambda$ is smaller than $\tilde{\psi}_{t, k}$. Here, ambiguity reinforces the Bayesian underestimation of the objective survival rates. For higher target ages the ambiguity part is higher than the additive probability. The resulting overestimation does not stem from more experience. It is due to the fact that unconditional survival rates for high target ages are eventually lower than the size of ambiguity $\lambda$. For an old agent (right panel in figure 2) the Bayesian conditional probability $\tilde{\psi}_{t, t+1}$ has become lower and the older agent is more ambiguous (high $\delta_{h}$ ) leading to a more horizontal subjective probability line in the figure. Thus, the ambiguity effect is more pronounced. In addition, the overestimation will occur sooner than for a young agent.

When surviving to the next period the agent gains more experience leading to a rise of ambiguity $\delta_{h}$ from equation (6). The function of $\delta_{h}$ is concave and converges to a value of 0.64 at the last year alive. Thus, with higher age the agents put more weight on the optimism parameter $\lambda$.

To summarize: The survival rates are characterized by an initial underestimation and a standard Bayesian learning process. On the other hand, ambiguity leads to an underestimation of near term survival rates and to an overestimation of further away survival probabilities at all ages. For young agents the underestimation effect is strong while for older agents the overestimation effect might dominate.

\section{Subjective and objective survival rates}

In this section both effects are taken together to compare the subjective probabilities with their objective counterparts. The agent makes her life-cycle plan with constant experience but gains more experience as she grows older. Rising experience has two effects on subjective belief formation: By Bayesian learning the agent can eventually better predict her survival rate. But at the same time her ambiguity rises, so that more weight is put on the ambiguity parameter $\lambda$ in equation (4). With a relatively low optimism parameter of $\lambda=0.386$ from the estimates of Ludwig and Zimper (2010) it is obvious that the objective survival rate to survive to the next period is always higher, implying an initial underestimation at all ages. But unconditional survival probabilities turn to values well below $\lambda$ implying an overestimation eventually (figure 3 ).

The panels in the figure show survival rate functions viewed from different plan- 
Figure 3: Unconditional probabilities
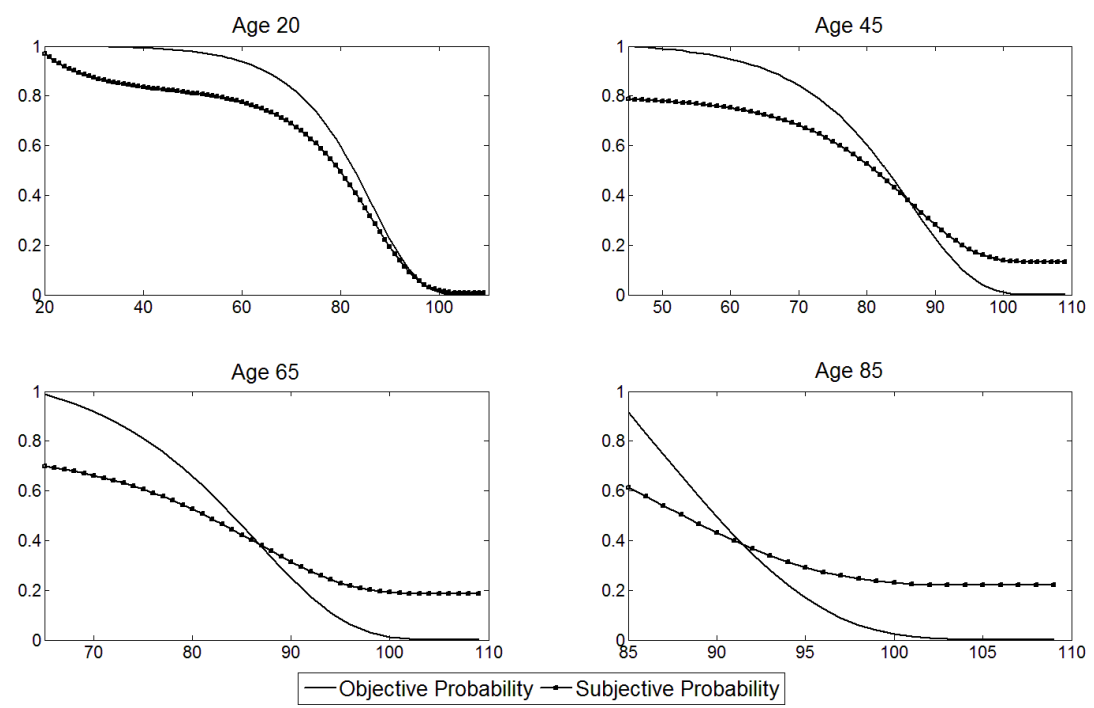

ning ages where target age $k$ is depicted on the $\mathrm{x}$-coordinate. In each of the panels experience and thus ambiguity is constant. In line with Hammermesh (1985), the survival function is generally flatter than its objective counterpart. The figure confirms that for younger ages the underestimation of the objective probabilities dominate while for old agents the overestimation becomes more pronounced.

Note, that the initial underestimation in every period comes from both the Bayesian underestimation and the ambiguity part of the decision theoretic model. The deviation from the additive probability (ambiguity) is linear (cf. figure 2). This model is a special case of the more general framework developped in prospect theory (see Wakker (2010, p. 205ff.)). According to this theory people assign specific weights to additive probability resulting in specific probability weighting functions. A common finding is that people seem to put more weight on low probability events and less weight on high probability events resulting in an inverted s-shaped weighting function if one assumes that the 45-degree line represents equality of the probability weighting function and the true probability similar to figure 2 . This observation perfectly fits into the observed pattern of subjective survival rates. Ludwig and Zimper (2010) use a linear approximation of the decision weighting function to be able to apply the model into a dynamic context.

\subsection{Subjective beliefs vs. rational expectations}

We compare the CEU model with subjective survival beliefs with an RE model as a benchmark using objective survival data. To isolate the effect of the decision 
theoretic model on life-cycle consumption and savings behavior we perform a ceteris paribus analysis. We assume the CEU model to be the right model and consider the calibrated preference parameter $\rho$ as a deep structural parameter which will be used for all other types of agents. The only difference between the CEU agent and the $\mathrm{RE}$ agent is that objective survival rates are used for the latter while all other preference parameters stay constant. This calibration strategy allow us to single out the effects of subjective survival belief formation on household saving behavior over the life cycle. We also discuss the possibility to recalibrate the parameter for the RE agent.

\section{Life-cycle profiles}

The agent enters the model at age 20 and makes a plan about her whole life. The RE agent with perfect foresight sticks to this initial plan, so that realized and planned variables always coincide. Contrary, the CEU agent with subjective survival only

Figure 4: Life-cycle decisions: Plans and realizations of an agent of age 20
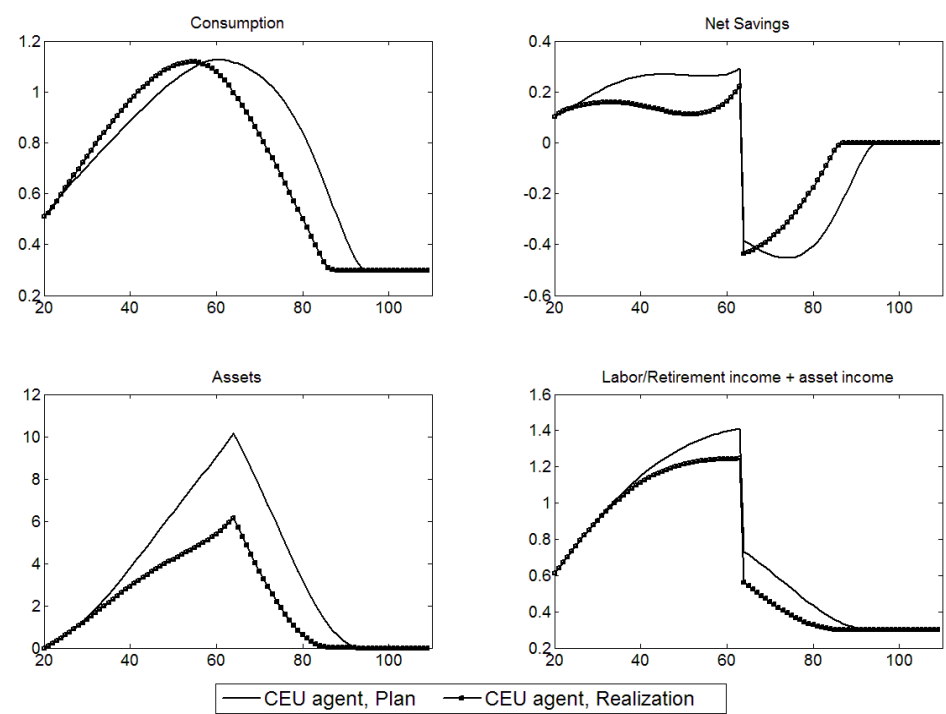

executes the first period of her plan. In the next period, she gets new information and updates her survival beliefs. This leads to a entirely revised consumption and savings plan. Ex-post one can generate the realized life-cycle profile of the CEU agent out of each of these plans and compare these to the initial plans, see figure 4 . Initially, the CEU agent plans to save much more and consume less during working life (except for the first three periods) resulting in much higher assets. We can thus replicate empirical findings reviewed above that people save less than they plan or think they should do. 
In figure 5 the planned and realized consumption profiles viewed from different planning ages are depicted. Note, that there is always underconsumption in the first

Figure 5: Life-cycle consumption: Plans and realizations for agents of age 20, 40, 60 and 80
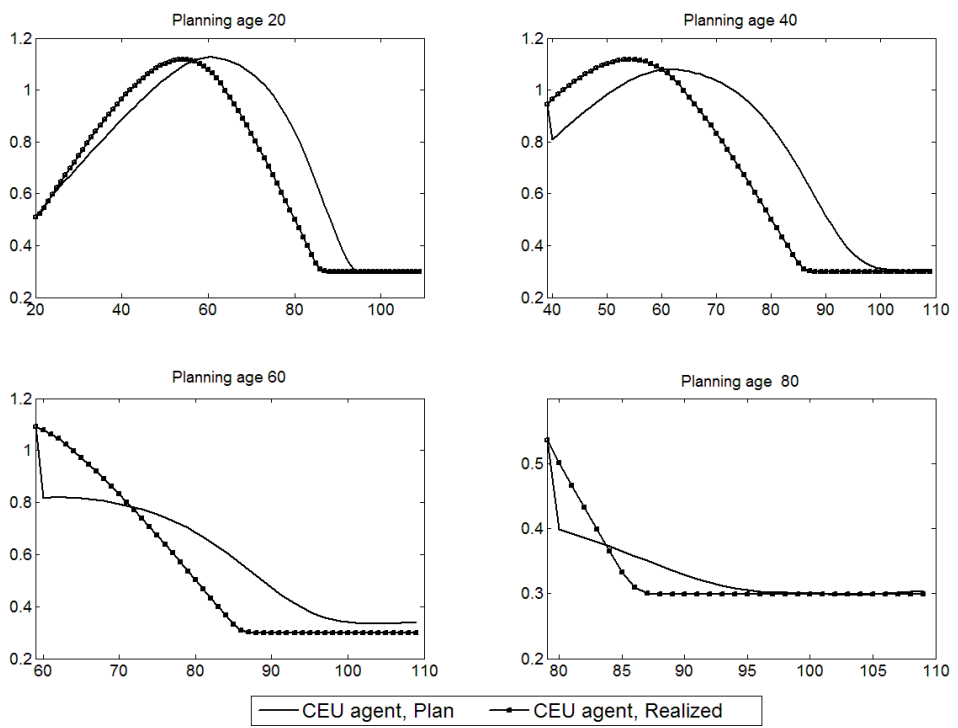

periods with an initial jump at the first to second period. This is due to the fact that the agent initially underestimates the probability to survive to the next period by huge amounts. With increasing age the overconsumption part occurs earlier and becomes more pronounced.

Figure 6 compares the realized CEU pattern with a standard life-cycle model with rational expectations (RE). The CEU agent exhibits undersaving until closely after retirement at age 68 relative to the $\mathrm{RE}$ agent. ${ }^{17}$ The savings rate of the CEU agent during her working life is 7.9 percentage points lower than the savings rate of the $\mathrm{RE}$ agent, compare table 3. Moreover, retired CEU agents dissave much less, than $\mathrm{RE}$ agents albeit at high rates. Accordingly, the agents with subjective probabilities exhibit overconsumption at younger ages and underconsumption starting at age 57 already. Overconsumption at younger ages leads to a much lower degree of asset accumulation. Assets of the CEU agent are, by the time of retirement, only a little more than half as much as the assets of a RE agent. Thus, total per period income defined as current labor or retirement income plus asset income is lower for the CEU agent throughout her life. Finally, the borrowing constraints binds much earlier for the CEU agents.

Comparing the RE agent with the CEU agent assuming the same preference pa-

\footnotetext{
${ }^{17}$ To be precise the CEU agent actually dissaves more from ages $65-68$.
} 
Figure 6: Realized life-cycle profile: RE versus CEU
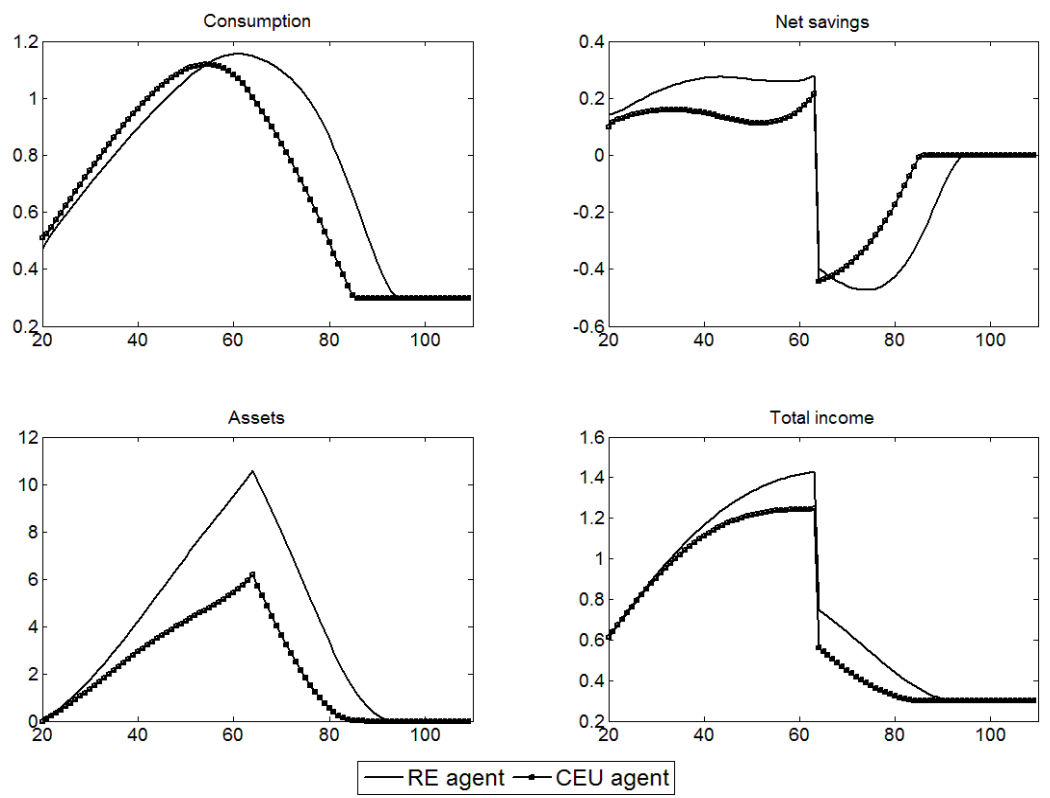

Table 3: Consumption and Savings: RE versus CEU

\begin{tabular}{lll}
\hline \hline & $R E$ model & CEU model \\
\hline Ratio of max. consumption $^{1)}$ & 1.95 & 1.79 \\
Age at max. consumption & 61 & 54 \\
Savingrate $^{2)}$ & $21.3 \%$ & $13.4 \%$ \\
Rate of dissaving $^{2)}$ & $53.9 \%$ & $38.1 \%$ \\
\hline 1) Maximal consumption relative to consumption at age 25 & \\
2) The average Savingrate is $\sum s_{t} / \sum y_{t}$ where $s_{t} \geq 0$ and the average dissaving rate is where $s_{t}<0$
\end{tabular}

rameter we observe a lower ratio of maximum consumption relative to consumption at age 25 as well as an earlier peak of this maximum consumption. In addition we observe a much lower saving rate during working life of a CEU agent at an average rate of $13.4 \%$ vs. $21.3 \%$ for a $\mathrm{RE}$ agent. Moreover, the average rate of dissaving of the CEU agent is $38.1 \%$ and much lower than the dissaving rate of $53.9 \%$ of the RE agent.

The implication of the decision theoretic model on life cycle patterns of consumption and savings can account for less saving during working life and less dissaving at old ages compared to a rational expectations agent. In addition, due to time inconsistency it allows deeper insights into life-cycle savings plans compared the actual decisions. Firstly, we observe that CEU agents plan to save more during working life than they actually do as suggested by survey evidence. Secondly, the CEU model can indeed contribute to some of the evidence of undersaving. The RE 
model can be interpreted as an ideal consumption profile the agent would choose if she was perfectly informed. Since the CEU agent consumes more and saves less during her working life, this may account for the evidence about undersaving reviewed in section 2. Also, it can be noted that the CEU agent dissaves less than the RE agent.

\section{Recalibrating the preference parameter}

The results of the previous section were presented for a calibration using the same preference parameter $\rho$ for both type of agents to concentrate on the effect of using subjective survival rates in a life-cycle model. On the other hand, this approach does not allow us to compare the two models to the data. The reason is that the RE model with a preference parameter $\rho$ calibrated for the CEU model leads to more savings and this to a higher capital output ratio than observed in the real world.

If the models were to be compared to the data one would need to recalibrate the RE model. But note that recalibrating $\rho$ to match $\frac{K}{Y}$ would precisely equalize the underlying willingness to save of the RE and the CEU consumers. Instead, we are interested in the effect of how subjective survival rates alter the decision of households. Recalibrating the $\mathrm{RE}$ model leads to a discount rate $\rho^{R E}=5 \%$ much larger than the discount rate for the CEU agent with $\rho^{C E U}=3.6 \%$ The resulting life-cycle profiles do not exhibit undersaving at younger ages and less dissaving at older ages. The underestimation of the survival rates for the CEU agent are now matched with a lower discount rate for the RE agent both operating quite similar.

To compare the two models one could also study which of the calibrated discount rates are within a range a plausible parameters. But unfortunately discount rates in the range of $3-5 \%$ seem perfectly reasonable.

\subsection{Subjective beliefs vs. self-control problems}

Undersaving for retirement can also be addressed with existing models of bounded self-control. The two most prominent models are temptation preference models developed by Gul and Pesendorfer (2001) and models of (quasi-)hyperbolic discounting, cf. Strotz (1956), Pollak (1968) and Laibson (1997).

Gul and Pesendorfer formalize the idea of temptation and self-control by two different utility functions: one describes commitment utility $u$ out of consumption while an additional function describes temptation utility $v$. Consumers per period utility is given by $U\left(c_{t}\right)=\max _{c_{t}}\left[u\left(c_{t}\right)+v\left(c_{t}\right)\right]-\max _{\tilde{c}_{t}} v\left(\tilde{c}_{t}\right)$, the sum of commitment 
and temptation utility less the temptation utility evalutated at the most tempting choice $\tilde{c}_{t}$. In a life-cycle setting $c_{t}$ is period consumption and the most tempting alternative $\tilde{c}_{t}$ might be defined as consuming all cash-on-hand in a given period. Thus, saving for retirement leads to cost of self-control of $\max _{\tilde{c}_{t}} v\left(\tilde{c}_{t}\right)-v\left(c_{t}\right)$. Thus, savings are lower than for the fully rational agent without self-control problems. In applications, the functional form is usually simply $v(c)=\lambda u(c)$ where $\lambda$ reflects the degree of temptation in the utility function. Of course, if one wants to quantify undersaving phenomena one needs to find an appropriate value for $\lambda$ which is - as with all preference parameters - hard to measure.

Similarly, a body of literature has modified the widely used assumption of exponentially discounting the future established by Samuelson (1937). The so-called (quasi-)hyperbolic discount function is a famous example with the aim to capture the empirically observed fact that people are more impatient than suggested by the exponential discounting model with a higher demand for instantaneous gratification (see Laibson (1997), O'Donoghue and Rabin (1999)). The discrete time quasi-hyperbolic function takes values $\left\{1, \gamma \beta, \gamma \beta^{2}, \gamma \beta^{3}, \ldots \gamma \beta^{T}\right\}$ where $0<\gamma, \beta<1$. In numerical simulations the short term preference parameter $\gamma$ is set to values between 0.6 and 0.85 (see, e.g. Laibson et al. (1998)).

The quasi-hyperbolic discounting model comes closest to the subjective survival belief model studied in this paper so we will compare the two models in more detail. The similarity can be seen by comparing the quasi-hyperbolic function with parame-

Figure 7: Survival rates and discount functions

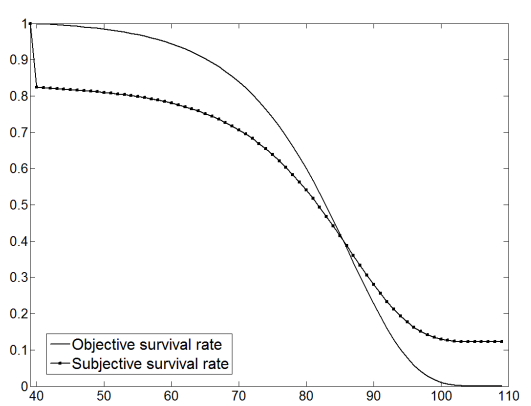

Unconditional survival rates

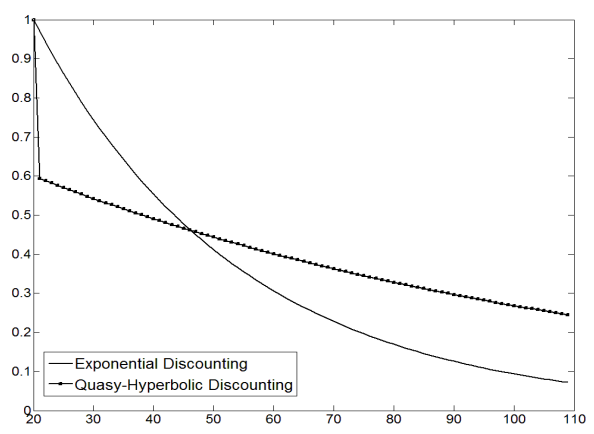

Discount functions

ters used in the literature to the subjective probability function. Figure 7 shows the quasi-hyperbolic discount function compared to the exponential case (right panel) and the subjective survival rate function compared to the life table data (left panel, starting at age 40). ${ }^{18}$ Both the subjective survival rate and the quasi-hyperbolic

\footnotetext{
${ }^{18}$ The first period in both panels is assumed to be the present, thus the survival rate and the
} 
function exhibit an initial downward jump from the present period to the next. In the following periods, both functions are generally flatter than their counterpart used in standard rational expectations agent models. Thus, both the hyperbolic discount factor and the subjective survival belief are higher in the distant future implying a relatively higher weight on future utility in both models. ${ }^{19}$

When calculating lifetime utility both the discount factor and the survival rate are used as weights for each period. Thus, the effect of our model of subjective survival beliefs and the quasi-hyperbolic discounting model are much alike. By choosing an appropriate short term discount factor $\gamma$ it is possible to generate lifecycle profiles that are similar to ours. Let the effective discount function of the CEU be $\nu_{h, t} \beta^{t-h}$ and $\psi_{h, t} \gamma \beta^{t-h}$ for the hyperbolic agent for each planning period $h$. Choose $\gamma$ to minimize the Eucleadian distance of the two discount functions (for every plan):

$$
\min _{\gamma} d_{2}=\min _{\gamma} \sum_{h=1}^{T} \sum_{t=1}^{T}\left[\nu_{h, t} \beta^{t-h}-\psi_{h, t} \gamma \beta^{t-h}\right]^{2}
$$

With a resulting short-term preference factor of $\gamma=0.822$ we get an effective discount function as shown in figure 8. Note that the effective discount functions of the

Figure 8: Quasi-hyperbolic agent and CEU agent with exponential discounting
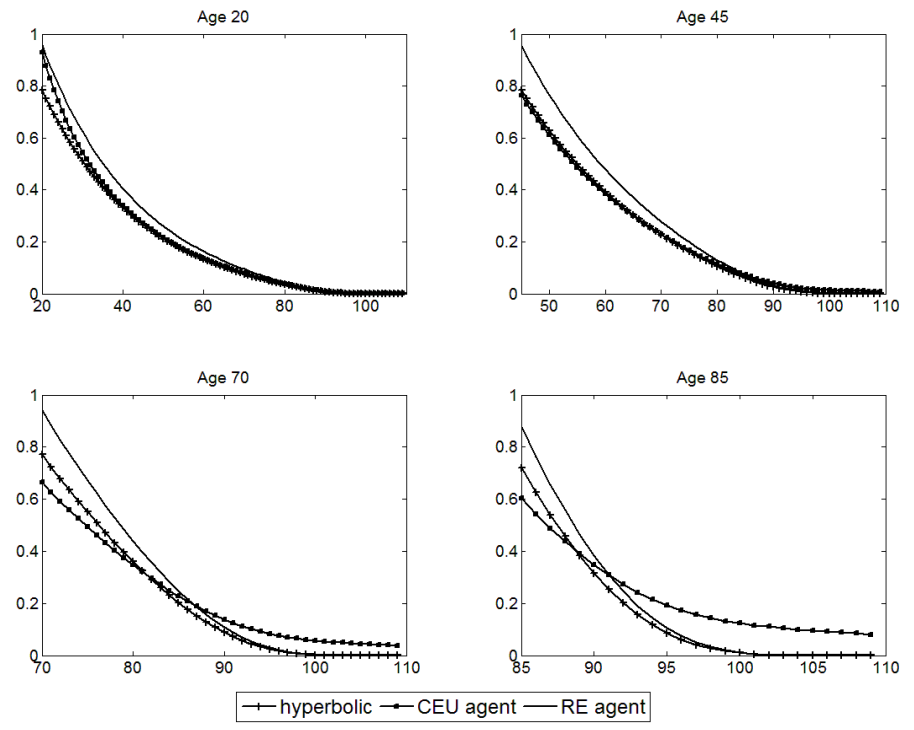

hyperbolic and the CEU agent are quite similar at younger ages, the CEU function discount factor is 1 .

${ }^{19}$ However, this depends on parametrization. It holds for different time preference rates $\beta$ for hyperbolic and exponential discounting. For the figure we arbitrarily set $\gamma=0.6$ and $\beta=0.99$ for hyperbolic discounters and $\gamma=1$ and $\beta=0.97$ in case of rational expectations. 
being closer to the agent with rational expectations than the hyperbolic function. Meanwhile, the CEU function gets flatter as the agent gets older. At all ages the

Figure 9: Quasi-hyperbolic and exponential discounting
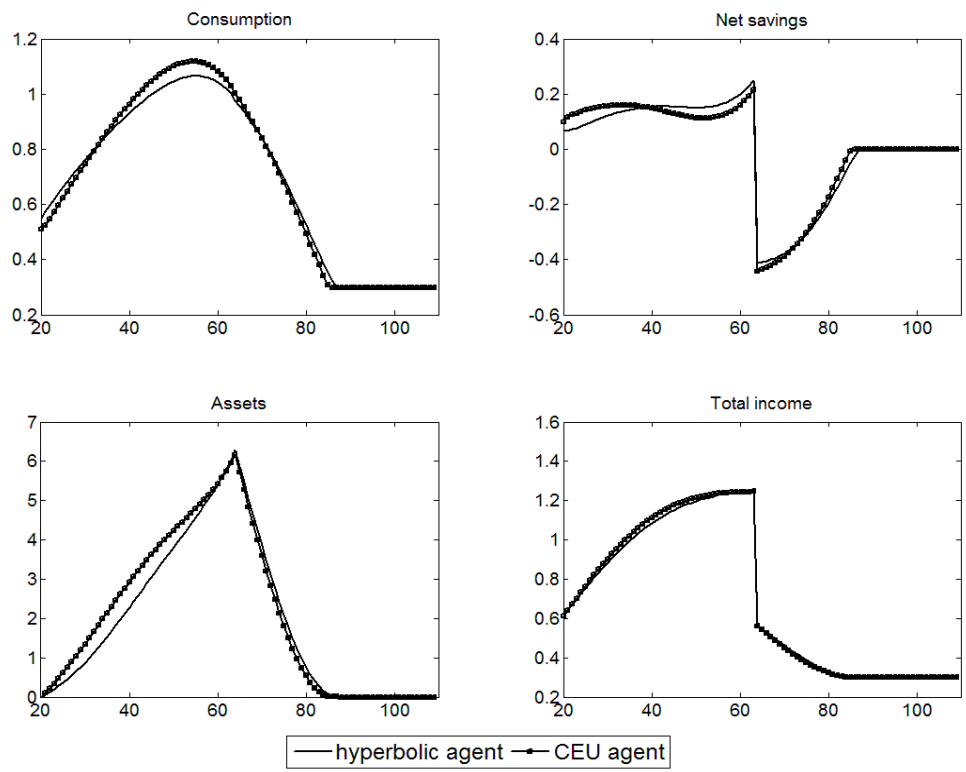

CEU function exhibits an overestimation at older ages that is not present in the hyperbolic model as we assumed the same standard discount factor $\beta$ throughout. Nevertheless, the resulting life-cycle profiles are very similar, see figure 9. According to the discount functions, the CEU agent saves more at younger ages as her discount factor is higher than for the hyperbolic agent. The opposite occurs in the middle ages where the (short term) effective discount factor of the CEU agent is lower leading to more consumption.

Despite the similarities we belief that the subjective survival model is different compared to the quasi-hyperbolic model with respect to two important aspects. First, the subjective survival belief model is based on a decision theoretic framework giving a microeconomic foundation. Contrary, the quasi-hyperbolic discounting model assumes a new ad-hoc discount function. Second, the parameters $\Psi=[\phi, \delta, \lambda]$ are easy to estimate by matching the subjective survival rates to the data. Again, the short-term discount factor assumed in the quasi-hyperbolic function is hard to measure and vary widely in the literature. This second argument becomes even more important in quantitative models evaluating e.g. welfare effects of social security for hyperbolic agents. 


\section{Concluding remarks}

This paper studies the implications of subjective survival beliefs for consumption and savings behavior. We map a decision theoretic model on survival belief formation developed by Ludwig and Zimper (2010) into a stochastic life-cycle model and compare the effects of subjective belief formation on life-cycle economic decision making. The CEU model of subjective beliefs is applicable and shows significant deviations from a model with rational expectations. In our model agents exhibits time inconsistency by not holding on to her plan leading realized savings to differ from last periods plan. In our main results we show that CEU agents save less at younger ages than they actually planned to save and they save less than an agent with rational expectations. In addition, CEU agents dissave less after retirement. With given parameters the CEU agent saves at a rate of 13.3 during her working life compared to a saving rate of 21.1 percent for the RE agent. The agent starts to consume less much earlier at age 57. At older ages, the CEU dissaves less with a dissaving rate of -38 percent compared to -53.6 for the RE agent. Overall, the model can account for three empirical findings at once: (i) time inconsistency of agents, (ii) undersaving at younger ages and (iii) less dissaving at older ages.

In the benchmark model, the life-cycle profiles of the CEU are observationally similar to the quasi-hyperbolic discounting model. However, we emphasize two important differences. First, our model is based on information rather than additional preference parameters like the hyperbolic discounting model. This means that the parameters needed to calibrate our model are much easier to estimate. Second, the subjective survival belief model is based on a sound decision theoretic framework.

We expect further differences once we extend the model in several aspects. Extending the life-cycle model with warm glow altruism is expected to lead to very different predictions from the two behavioral models. A warm-glow bequest motive offsets part of the undersaving of the ambiguity psychologically biased agent because her pessimism with respect to survival increases the effective weight of utility from leaving bequests. However, overall asset accumulation remains lower than for the fully rational agent. In contrast, the hyperbolic discounting model predicts lower asset accumulation than the learning model because the present bias decreases the utility weight on old-age consumption as well as intended bequests. Another difference of the two models emerge when introducing a structural break of the survival rates. Assume the agent exhibit an unanticipated positive shock of his survival rates due to e.g. the invention and wide use of antibiotics as discribed in Jayachandran et al. (2010). While this shock translates into a sudden change of behavior for the 
hyperbolic agent we expect a smoother reaction for the CEU agent. This is due to the fact that the agent will probably consider only parts of this sudden new information about her surival probability when forming her survival beliefs. We leave the discussion on the two alternative models at this descriptive stage and relegate a more in-depth empirical analysis to discriminate between both models to future research.

In future work we also intend to study welfare consequences of social security in a life-cycle model with subjective survival beliefs. A simulation study with the hyperbolic discounters from Laibson et al. (1998) evaluate large welfare gains of a defined contribution plan as a commitment device for a sophisticated hyperbolic consumer anticipating her time-inconsistent behavior. Contrary, a carefully calibrated dynamic stochastic general equilibrium model by Imrohoroğlu et al. (2003) finds that there are no welfare gains from social security with hyperbolic consumers having short-term discount rates around 10 to 15 percent. They conclude that social security is a poor commitment device to correct for undersaving of hyperbolic discounters, mainly due to negative aggregate economic effects. ${ }^{20}$ The key problem of calibrating these studies is that additional preference parameters reflecting the degree of present-bias are not observable and there is not much consensus concerning their values. As a consequence, the size of welfare effects of a pay-as-you-go social security system depends on the parameters chosen for the hyperbolic discount rate. In contrast, our model uses reliable estimates for the subjective survival beliefs model which makes the computation of welfare consequences of social security less dependend on hard-to-observe preference parameters.

\footnotetext{
${ }^{20}$ Finding an appropriate welfare criterion in models with non-rational behavior is an ongoing debate, see, among others, Bernheim and Rangel (2009).
} 


\section{References}

Aguila, E., Attanasio, O. and Meghir, C. (2011). Changes in consumption at retirement: Evidence from panel data, Review of Economics and Statistics 93(3): 1094-1099.

Ameriks, J. and Utkus, S. P. (2006). Vanguard retirement outlook 2006, Vanguard Center for Retirement Research.

Ando, A. and Modigliani, F. (1963). The 'life-cycle' hypothesis of saving: Aggregate implications and tests, Amercian Economic Review 53: 55-84.

Attanasio, O. P. and Hoynes, H. W. (2000). Differential mortality and wealth accumulation, Journal of Human Ressources 35 (1): 1-29.

Barsky, R. B., Juster, F. T., Kimball, M. S. and Shapiro, M. D. (1997). Preference parameters and behavioral heterogeneity: An experimental approach in the health and retirement study, Quarterly Journal of Economics 112(2): 537-579.

Bernheim, B. D. and Rangel, A. (2009). Beyond revealed preference: Choicetheoretic foundations for behavioral welfare economics, The Quarterly Journal of Economics 124(1): 51-104.

Bernheim, D. B. (1998). Financial illiteracy, education, and retirement saving, in O. S. Mitchell and S. J. Schieber (eds), Living with Defined Contribution Pensions, The Pension Research Council, pp. 38-68.

Bernheim, D. and Rangel, A. (2007). Behavioral public economics: Welfare and policy analysis with nonstandard decision-makers, in P. Diamond and H. Vartianen (eds), Behavioral Economics and Its Applications, Princeton University Press.

Bloom, D. E., Canning, D., Moore, M. and Song, Y. (2006). The effect of subjective survival probabilities on retirement and wealth in the united states, NBER Working Paper (12688).

Brown, J. R. (2007). Rational and behavioral perspectives on the role of annuities in retirement planning, NBER Working Papers 13537, National Bureau of Economic Research. 
Chateauneuf, A., Eichberger, J. and Grant, S. (2007). Choice under uncertainty with the best and worst in mind: Neo-additive capacities, Journal of Economic Theory 127: 538-567.

Choi, J. J., Laibson, D., Madrian, B. C. and Metrick, A. (2006). Saving for retirement on the path of least resistance, in E. J. McCaffrey and J. Slemrod (eds), Behavioral Public Finance: Toward a New Agenda, New York: Russell Sage Foundation, pp. 304-351.

De Nardi, M., French, E. and Jones, J. B. (2010). Why do the elderly save? the role of medical expenses, Journal of Political Economy 118(1): 39-75.

Doob, J. L. (1949). Application of the theory of martingales, Le Calcul des Probabilités et ses Applications, Colloques Internationaux du Centre National de la Recherche Scientifique 13: 23-27.

Engen, E. M., Gale, W. G. and Uccello, C. E. (1999). The adequacy of household saving, Brookings Papers on Economic Activity 1999(2): 65-187.

Friedman, B. M. and Warshawsky, M. J. (1990). The cost of annuities: Implications for saving behavior and bequests, The Quarterly Journal of Economics 105(1): 135-154.

Gahramanov, E. (2011). Survival misperceptions, time inconsistency, and implications for the life-cycle saving and welfare, Working Paper.

Gan, L., Gong, G., Hurd, M. D. and McFadden, D. L. (2004). Subjective mortality risk and bequests. NBER Working Paper No. 10789.

Gourinchas, P.-O. and Parker, J. (2002). Consumption over the lifecycle, Econometrica 70(1): 47-91.

Gul, F. and Pesendorfer, W. (2001). Temptation and self-control, Econometrica 69(6): 1403-1435.

Gul, F. and Pesendorfer, W. (2004). Self-control and the theory of consumption, Econometrica 72(1): 119-158.

Hammermesh, D. S. (1985). Expectations, life expectancy, and economic behavior, Quarterly Journal of Economics 100(2): 389-408. 
Harris, C. and Laibson, D. (2001). Dynamic choices of hyperbolic consumers, Econometrica 69(4): 935-957.

Hubbard, R. G., Skinner, J. and Zeldes, S. P. (1995). Precautionary saving and social insurance, The Journal of Political Economy 103(2): 360-399.

Huggett, M., Ventura, G. and Yaron, A. (2007). Sources of lifetime inequality, NBER Working Paper (13224).

Hurd, M. (1989). Mortality risk and bequests, Econometrica 57: 173-209.

Hurd, M. D., McFadden, D. L. and Gan, L. (1998). Subjective survival curves and life cycle behavior, Inquiries in the Economics of Aging, NBER Chapters, National Bureau of Economic Research, Inc, pp. 259-309.

Hurd, M. D. and Smith, J. P. (1999). Anticipated and actual bequests. NBER Working Paper No. 7380.

Hurd, M. and Rohwedder, S. (2010). Wealth dynamics and active saving at older ages: Do they add up, Mimeo.

Imrohoroğlu, A., Imrohoroğlu, S. and Joines, D. H. (2003). Time-inconsistent preferences and social security, Quarterly Journal of Economics 118(2): 745-784.

Jayachandran, S., Lleras-Muney, A. and Smith, K. V. (2010). Modern medicine and the twentieth century decline in mortality: Evidence on the impact of sulfa drugs, American Economic Journal: Applied Economics 2(2): 118-46.

Kaplan, G. and Violante, G. L. (2010). How much consumption insurance beyond self-insurance?, American Economic Journal: Macroeconomics 2(4): 53-87.

Kastenbaum, R. (2000). The Psychology of Death, Springer Publishing Company, New York.

Kopczuk, W. and Slemrod, J. (2005). Denial of death and economic behavior, The B.E. Journal of Theoretical Economics 5(1): Article 5.

Krüger, D. and Ludwig, A. (2007). On the consequences of demographic change for rates of return to capital and the distribution of wealth and welfare, Journal of Monetary Economics 54(1): 49-87.

Laibson, D. (1997). Golden eggs and hyperbolic discounting, The Quarterly Journal of Economics 112 (2): 443-477. 
Laibson, D. I. (1996). Hyperbolic discount functions, undersaving, and savings policy. NBER Working Paper No. 5635.

Laibson, D. I., Repetto, A., Tobacman, J., Hall, R. E., Gale, W. G. and Akerlof, G. A. (1998). Self-control and saving for retirement, Brookings Papers on Economic Activity 1998(1): 91-196.

Lee, R. D. and Carter, L. (1992). Modeling and forecasting U.S. mortality, Journal of the American Statistical Association 87 (419): 659-671.

Ludwig, A. and Zimper, A. (2010). A parsimonious model of subjective life expectancy. Working Paper.

Mitchell, O. S. and Utkus, S. P. (2005). Lessons from behavioral finance for retirement plan design, in O. S. Mitchell and S. P. Utkus (eds), Pension Design and Structure, New Lessons from Behavioral Finance, Oxford University Press, chapter 2.

Modigliani, F. and Brumberg, R. (1954). Utility analysis and the consumption function: An interpretation of cross-section data, in K. K. Kurihara (ed.), PostKeynesian Economics, Rutgers University Press, New Brunswick, pp. 388-436.

Munnell, A., Webb, A. and Golub-Sass, F. (2010). How will higher tax rates affect the national retirement risk index?, Brief of the Center for Retirement Research.

O'Donoghue, T. and Rabin, M. (1999). Doing it now or later, The American Economic Review 89(1): 103-124.

Peracchi, F. and Perotti, V. (2010). Subjective survival probabilities and life tables: Evidence from europe, Working Paper.

Pollak, R. A. (1968). Consistent planning, Review of Economic Studies 35: 201-208.

Preston, S. H., Heuveline, P. and Guillot, M. (2001). Domography - Measuring and Modelling Population Processes, Blackwell Publishers Ltd.

Puri, M. and Robinson, D. (2005). Optimism and economic choice. NBER Working Paper No. 11361.

Rubinstein, A. (2003). Economics and psychology? the case of hyperbolic discounting, International Economic Review 44(4): 1207-1216. 
Samuelson, P. A. (1937). A note on measurement of utility, The Review of Economic Studies 4(2): 155-161.

Schmeidler, D. (1989). Subjective probability and expected utility without additivity, Econometrica 57: 571-587.

Scholz, J. K., Seshadri, A. and Khitatrakun, S. (2006). Are americans saving "optimally" for retirement?, Journal of Political Economy 114(4): 607-643.

Siegel, J. J. (2002). Stocks for the Long Run: The Definitive Guide to Financial Market Returns and Long-Term Investment Strategies, New York: McGrawHill.

Storesletten, K., Telmer, C. and Yaron, A. (2004). Cyclical dynamics in idiosyncratic labor market risk, Journal of Political Economy 112: 695-717.

Strotz, R. H. (1956). Myopia and inconsistency in dynamic utility maximization, Review of Economic Studies 23 (3): 165-180.

Wakker, P. P. (2010). Prospect Theory: For Risk and Ambiguity, Cambridge University Press, Cambridge, UK. 


\section{Appendix}

\section{Mergeing subjective survival beliefs into a life-cycle model}

In this appendix we briefly describe how the decision theoretic model proposed by Ludwig and Zimper (2010) is merged into a life-cycle context. In particular we show how to derive the life-tyme utility funciton (3) together with the subjective survival belief (4).

Choquet Expected Utility (CEU) agents maximize expected utility with respect to non-additive beliefs represented by capacities. Capacities generalize the notion of probability distributions that do not need to satisfy additivity.

Definition $2 A$ capacity $v$ on the state space $S$ is a real-valued set function on the subsets of $S$ which satisfies (i) $v(\emptyset)=0, v(S)=1$ (normalization) and (ii) $A \subset B, A, B \in S, v(A) \leq v(B)$ (monotonicity).

Let $u$ be a strictly concave utility function, and $f$ some act, mapping from a set of states $S$ in some set of consequences $X$. For a given act $f$ denote by $s_{1}, \ldots, s_{m}$ the partition of $S$ such that $u\left(f\left(s_{1}\right)\right)>\ldots>u\left(f\left(s_{m}\right)\right)$.

Definition 3 The Choquet expected utility of an act $f$ with respect to capacity $v$ is defined by

$$
\mathbb{C} \mathbb{E} U(f, v) \equiv \sum_{i=1}^{m} u\left(f\left(s_{i}\right)\right) \cdot\left[v\left(s_{1} \cup \ldots \cup s_{i}\right)-v\left(s_{1} \cup \ldots \cup s_{i-1}\right)\right]
$$

We focus on Choquet expected utility with respect to non-additive beliefs that are defined as neo-additive capacities developed by Chateauneuf et al. (2007). Let $\chi(A)$ be some additive probability function and $\kappa^{o}$ and $\kappa^{p}$ two capacities representing complete optimism and pessimism specified below. A neo-additive capacity is then defined as a convex combination of these two capacities and the probability function $\chi(A)$.

Definition 4 (Chateauneuf et al. (2007)) A neo-additive capacity $\kappa$ with respect to some event $A \in \mathrm{S}$ is defined as:

$$
\kappa(A)=\delta\left(\lambda \kappa^{o}(A)+(1-\lambda) \kappa^{p}(A)\right)+(1-\delta) \chi(A),
$$


where the capacities $\kappa^{o}$ and $\kappa^{p}$ are defined as

$$
\begin{aligned}
& \kappa^{o}(A)=1, \text { for all } A \neq \varnothing \\
& \kappa^{p}(A)=0, \text { for all } A \varsubsetneqq \mathrm{S} .
\end{aligned}
$$

$\kappa^{o}$ represents complete confidence assigning one to every possible event, while $\kappa^{p}$ represents complete pessimism assigning zero to every uncertain event.

With these definitions it can be shown that the Choquet expected utility (CEU) function with respect to neo-additive capacities is given by:

$\mathbb{C E} \mathbb{U}(f, \kappa)=(1-\delta) \sum_{s \in S} u(f(s)) \cdot \chi(s)+\delta \cdot\left[\lambda \max _{s \in S} u(f(s))+(1-\lambda) \min _{s \in S} u(f(s))\right]$

The CEU function is a linear combination of von-Neuman-Morgenstern utility $\sum_{s \in S} u(f(s)) \cdot \chi(s)$ weighted with the factor $(1-\delta)$ and a second element representing ambiguity weighted with $\delta$. Ambiguity is modeled as a convex combination of the best and the worst possible outcome of acts. The weighting $\delta$ can be interpreted as a measure of how strong expected utility is biased by ambiguity. The parameter $\lambda$ measures how much weight the agent puts on the best possible outcome of act $f$ when resolving her ambiguity.

For translating this model into the life-cycle setting with two uncertainties (survival probability and labor productivity) we assume $s_{k}$ to be the state in which the agent dies in period $k$. Hence, there are $T$ relevant states $S=\left\{s_{1}, s_{2}, \ldots, s_{T}\right\}$. The additive part $\chi\left(s_{k}\right)$ is assumed to be some subjective probability to survive until period $k$, denoted by $\chi\left(s_{k}\right)=\tilde{\psi}_{t, k}$ specified in the main text. The objective survival probability cannot be observed by the agent. Expected utility from consumption is defined as the relevant acts $f(s)$. The outcome of each state is presented in table 4 where expectation is taken with respect to uncertain labor productivity $\eta$.

Table 4: Definition of states

\begin{tabular}{lccll}
\hline \hline state: & $s_{1}$ & $s_{2}$ & $\ldots$ & $s_{T}$ \\
\hline utility & $\mathrm{E}_{\eta}\left\{u\left(c_{1}\right)+\beta u\left(c_{2}\right)\right\}$ & $\mathrm{E}_{\eta}\left\{u\left(c_{1}\right)+\beta u\left(c_{2}\right)+\beta^{2} u\left(c_{3}\right)\right\}$ & $\ldots$ & $\mathrm{E}_{\eta}\left\{\sum_{t=1}^{T} \beta^{t-1} u\left(c_{t}\right)\right\}$ \\
\hline \hline
\end{tabular}

With these assumptions we can specify ambiguity by forming subjective survival beliefs, i.e., the best and the worst possible outcome, more precisely. The best possible outcome is the sum of utility flows if the agent would survive for sure in every period. The worst possible outcome represents utility if the agent would die 
for sure, implying zero utility by assumption. This is taken care of by assuming $\theta<1$ in the utility function.

The CEU function (10) viewed from the planning period $h \leq t<k$ can be rewritten to:

$$
\mathbb{C} \mathbb{E} \mathbb{U}_{h}=\lambda \delta_{h} \sum_{k=t}^{T} \beta^{k-t} \mathrm{E}_{\eta}\left[u\left(c_{k}\right)\right]+\left(1-\delta_{h}\right) \sum_{k=t}^{T} \beta^{k-t} \tilde{\psi}_{t, k}^{h} \mathrm{E}_{\eta}\left[u\left(c_{k}\right)\right] .
$$

This equation can be transformed into the lifetime utility function (2):

$$
\mathbb{C} \mathbb{E} \mathbb{U}_{h}=\sum_{k=t}^{T} v_{t, k}^{h} \beta^{k-t} \mathrm{E}_{\eta}\left[u\left(c_{k}\right)\right]
$$

where $\mathbf{E}_{\psi}\left[\psi_{t, k}\right]=v_{t, k}$ is denoted as the subjective belief to survive from period $t$ to period $k$, planned in period $h$, given by:

$$
\nu_{t, k}^{h}=\delta_{h} \cdot \lambda+\left(1-\delta_{h}\right) \tilde{\psi}_{t, k}^{h}
$$

These are the equations given in the main text.

\section{Proof of Proposition 1}

Time inconsistency is present if the marginal rate of substitution $(M R S)$ between two periods depends on the planning period. The natural way to show time inconsistency is to compare the $M R S$ for any two different planning periods. In $t=0$ we have

$$
C E U_{0}=u\left(c_{0}\right)+\beta \nu_{0,1} u\left(c_{1}\right)+\beta^{2} \nu_{0,2} u\left(c_{2}\right)+\ldots+\beta^{T} \nu_{0, T} u\left(c_{T}\right)
$$

So the marginal substitution between consumption in period 1 and 2, planned in period 0 is given by:

$$
M R S_{c_{1}, c_{2}}^{0}=\frac{1}{\beta} \frac{v_{0,1}}{v_{0,2}} \frac{u_{c_{1}}}{u_{c_{2}}}
$$

In Period $t=1$ the utility function is

$$
C E U_{1}=u\left(c_{1}\right)+\beta v_{1,2} u\left(c_{2}\right)+\beta^{2} v_{1,3} u\left(c_{3}\right)+\ldots+\beta^{T} v_{1, T} u\left(c_{T}\right)
$$

implying for the $M R S_{c_{1}, c_{2}}^{1}$ for consumption in period 1 and 3 to be

$$
M R S_{c_{1}, c_{2}}^{1}=\frac{1}{\beta} \frac{1}{v_{1,2}} \frac{u_{c_{1}}}{u_{c_{2}}}
$$


It is immediately clear that the $M R S$ are not equal because:

$$
v_{0,2} \neq v_{0,1} \cdot v_{1,2}
$$

On the other hand, for the rational expectations agent the unconditional probability to survive from period 0 to 2 is just the product of the two conditional survival rates, $\pi_{0,2}=\pi_{0,1} \cdot \pi_{1,2}$. This leads to a marginal rate of substitution between two periods which is independent on the planning period.

Note, that for the non-anticipating agent the Bayesian learning probability alone leads to time inconsistency. This is because the non-anticipating agent makes his plan with constant experience making the Bayesian probability dependent on the planning period. For the two planning periods $h$ and $h+i$ we have

$$
\begin{aligned}
\tilde{\psi}_{t, k}^{h} & =\left(\frac{2 \phi^{k-t}+n(h)}{2+n(h)}\right) \psi_{t, k} \\
\tilde{\psi}_{t, k}^{h+i} & =\left(\frac{2 \phi^{k-t}+n(h)+i}{2+n(h)+i}\right) \psi_{t, k} .
\end{aligned}
$$

The anticipating agent (SCEU) foresees that she will gain experience, making the Bayesian probability independent on the planning period:

$$
\tilde{\psi}_{t, k}^{S C E U}=\left(\frac{2 \phi^{k-t}+t}{2+t}\right) \psi_{t, k}
$$

The anticipating agent still exhibit time inconsistency due to the non-additive nature of her subjective survival beliefs. 